\title{
THE IMPACT OF EMOTIONAL INTELLIGENCE IN THE CONTEXT OF LANGUAGE LEARNING AND TEACHING
}

\section{ElenaSpirovska Tevdovska}

South East European University, e.spirovska@seeu.edu.mk

DOI: $10.1515 /$ seeur-2017-0009

\section{Abstract}

Emotional intelligence, a set of skills which are considered as necessary in the context of interaction with other people, was defined by a number of authors, including Goleman (1996), Gardner and Mayer \& Salovey. Anumber of studies investigated the impact of emotional intelligence on learning, teaching and education. The focus of this article is to explore the definition of emotional intelligence and the impact that emotional intelligence and affective factors have in the context of foreign language learning and teaching. The article also focuses on research conducted with a group of 23 students and their self assessment of emotional intelligence as well as their perceptions of the ways emotional intelligence has an impact on foreign language learning. The article attempts to provide recommendations of implementing activities and teaching practices in the context of foreign language learning and teaching aiming to foster emotional intelligence development.

Key words: emotional intelligence, learning, language learning, teaching practices 


\section{Defining The Impact Of Emotional Intelligence}

The concept of emotional intelligence was introduced and analyzed by a number of authors, including Goleman, Gardner and Mayer \& Salovey. The notion, which stirred interest and attention, was divided by Mayer \& Salovey (1997) into two component terms: intelligence and emotion. According to them, the cognitive sphere, or intelligence, includes functions as: "human memory, reasoning, judgment and abstract thought" and the emotional aspect includes: emotions themselves, moods, evaluations and other feeling states, including fatigue and energy" (Mayer \& Salovey, 1997, p.4). However, they emphasize that not everything which connects cognition or emotion is related to emotional intelligence and propose a definition which describes emotional intelligence as a criterion that refers to: "heightened emotional or mental abilities" (Mayer \& Salovey, 1997, p.9). Salovey \& Mayer, (1990, p.189) in their earlier work, define emotional intelligence as follows: "We define emotional intelligence as a subset of social intelligence that involves the ability to monitor one's own and others' feelings and emotions, to discriminate among them and to use this information to guide one's thinking and actions".

Mayer \& Salovey (1997) devised a diagram presenting emotional intelligence skills which accurately depict the psychological processes.

According to them, the lower branch in the diagram is the ability of perceiving and expressing emotions, such as perception, appraisal and expression of emotions. This branch includes the ability to identify emotions in the self and in others, to express emotions accurately and to distinguish between accurate or inaccurate.

Higher branches involve emotional facilitation of thinking, which involves directing attention, forming judgment and allowing emotional states to encourage specific problem approaches.

Even higher positioned branch in the diagram represents understanding and analyzing emotions and employing emotional knowledge, which involves the ability to label emotions and interpret meaning of emotions convey, ability to understand complex feelings and transitions between emotions.

Finally, the highest branch in the emotional intelligence diagram involves reflective regulation of emotions to promote emotional and intellectual growth. This includes the ability to stay open to various feelings, to effectively monitor emotions and to manage emotions by fostering positive and moderating negative emotions. 
The diagram is presented below:

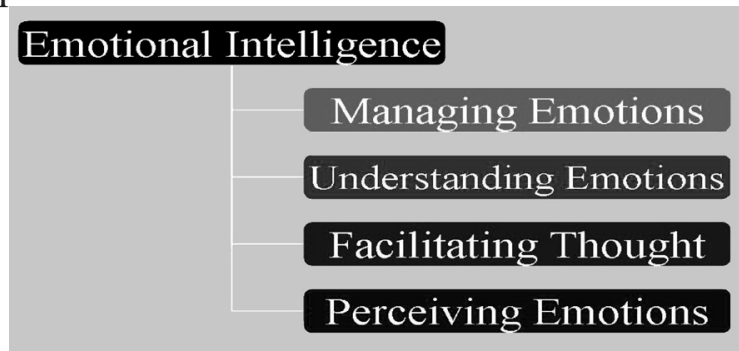

Figure 1. Ability model of emotional intelligence (adapted from Mayer, J.D, 2012)

Emotional intelligence is discussed and defined by Goleman (1995), who defines the notion as follows: " ... being able, for example, to reign in emotional impulse; to read another's innermost feelings, to handle relationships smoothly- as Aristotle put it, the rare skill 'to be angry with the right person, to the right degree, at the right time, for the right purpose, and in the right way' (Goleman, 1995, p.13). The major purpose of emotional intelligence development, according to Goleman (1995), is focusing on the following

- Development of self awareness : recognizing feelings and being able to express them, recognizing one's strengths and weaknesses, being able to perceive consequences and being able to see oneself in positive but realistic lights.

- Self regulation and managing emotions: realizing where certain feelings originate from and being able to cope with them, taking responsibility for actions and mistakes and honoring commitments.

- Developing social skills: the ability to understand other people, leadership skills, ability to find solutions and to establish personal relationships, being able to detect people's feelings and motivations.

- Developing empathy and understanding others' reactions and emotions, which includes respecting differences, learning to listen attentively and learning to cooperate or resolve a conflict.

In the study conducted by Carmeli (2003) a positive link is established between emotional intelligence and work attitudes. It is established that the emotional intelligence in individuals has a positive impact on their job satisfaction. In addition, the study shows that emotional intelligence significantly influences individuals' work commitment and the five components of work commitment (work ethic endorsement, career commitment, affective organizational commitment, continuance organizational commitment and job involvement). Carmeli (2003) also investigates the link between emotional intelligence and organizational commitment, which incorporates three different concepts: 
- affective (positive feelings and involvement with organization)

- continuance (commitment of individuals to their organizations based on costs and financial consequences if they leave)

- normative commitment (commitment based on a sense of obligation to institutions)

Carmeli (2003) also investigated the influence of emotional intelligence of work outcomes and performance. The study proved that emotionally intelligent individuals are more committed to their careers, tend to be more satisfied and are less likely to withdraw from a position.

From the definitions and descriptions above, it is clear that development of emotional intelligence is a very important step in individual development, learning. In addition, it is obvious that emotionally intelligent individuals have better prospects in terms of successful careers, job satisfaction and work commitment. However, the questions this article attempts to answer are the following:

Taking into consideration the importance of emotional intelligence, is it possible to improve the emotional intelligence characteristics in the process of education? Is it possible to incorporate practices and activities which support emotional intelligence development in formal educational settings? More specifically, is it possible to introduce programs of emotional intelligence development in language learning and how? Would introducing these elements of development enrich the existing educational curricula?

\section{Emotional Intelligence And Affective Factors In Language Learning}

Establishing the link between emotional intelligence and language learning, as well as learning in general is also among the aims of this article. Therefore, the following research questions can be developed:

- Is there a link between emotional intelligence and language learning?

- How can emotional intelligence development be supported in language learning process?

In a study conducted by Marquez, Martin \& Bracket (2006), the link between academic accomplishments and emotional intelligence was investigated. The study supported the claim that emotional intelligence boosted social and academic accomplishments in the given setting, which, in this case, was for high school students. The study showed that there is a positive link between emotional intelligence and the academic and social development of adolescents. 
ZarafshanandArdeshiri(2012) investigated the effects of emotional intelligence and use of language learning strategies on English language proficiency among Iranian EFL students. Their study showed that metacognitive, affective and social learning strategies, in addition to emotional intelligence, contributed positively to English language proficiency.

Pishghadam (2009) examined the role of emotional intelligence in language learning. His study also compared the emotional intelligence and students' scores in language skills: reading, speaking, listening and writing, as well as students' GPA. The findings and the recommendations indicated that a higher level of EQ was a significant predictor of a higher GPA. The higher level of EQ was also linked to higher scores in language skills, which significantly depend on emotional intelligence abilities: reading (which depends on stress management, adaptability and general mood), listening (which was linked to interpersonal skills and stress management), speaking (linked to interpersonal and intrapersonal skills), as well as writing (connected to adaptability and stress management).

\section{Emotional Intelligence Tested -Research And Students' Responses}

The participants of this study were 23 students enrolled at the English Language Teaching MA program offered by South East European University in Tetovo, Republic of Macedonia. Their age varies from 23-44 years of age. Out of 23 participants 6 are male and 17 are female. The participants in the program are foreign and second language learners and future teachers of EFL/ ESL courses in different setting. The purpose of the research was to assess their perceptions of their emotional intelligence

The method of research applied was self-rating level of emotional intelligence after the students were asked to complete the Emotional Intelligence Questionnaire, developed by Anaptys, The Development Practice (2013), and downloaded from the following link: http://www.centralpho.org.nz/Portals/0/ Health $\% 20$ Services/Transformational\%20Leadership/Emotional\%20 Intelligence \%20Questionnaire.pdf

The five aspects of emotional intelligence, identified by Goleman (1996) are rated and analyzed:

- Self awareness

- Self regulation

- Motivation

- Empathy

- Social skills 
The students were asked to take the inventory and self-assess the aspects of emotional intelligence. Lower average results indicated that according to self-assessment, the individuals consider themselves to be emotionally intelligent. Higher average results indicated that the individuals need to work on improving the aspects of their emotional intelligence. Afterwards, the participants were asked, in an informal interview, to analyze the scores and provide their opinion on the emotional intelligence traits that they believe can be improved.

The following table shows the number of participants who reported the average scores on the emotional intelligence aspects:

\begin{tabular}{|c|c|c|c|c|c|c|}
\hline \multicolumn{2}{|c|}{$\begin{array}{l}\text { Table } 1 \\
\text { The average scores } \\
\text { on the emotional } \\
\text { intelligence aspects }\end{array}$} & \multirow[b]{2}{*}{$\begin{array}{l}\text { Average } \\
\text { score } 5\end{array}$} & \multirow[b]{2}{*}{$\begin{array}{l}\text { Average } \\
\text { score } 4\end{array}$} & \multirow[b]{2}{*}{$\begin{array}{l}\text { Average } \\
\text { score } 3\end{array}$} & \multirow[b]{2}{*}{$\begin{array}{l}\text { Average } \\
\text { score } 2\end{array}$} & \multirow[b]{2}{*}{$\begin{array}{l}\text { Average } \\
\text { score } 1\end{array}$} \\
\hline Dimension & $\begin{array}{l}\text { Average } \\
\text { score } 6\end{array}$ & & & & & \\
\hline Self-awareness & $\begin{array}{l}3 \\
\text { participants }\end{array}$ & 5 & 5 & 4 & 4 & 2 \\
\hline Self regulation & $\begin{array}{l}4 \\
\text { participants }\end{array}$ & 4 & 6 & 5 & 2 & 2 \\
\hline Motivation & \begin{tabular}{|l}
5 \\
participants \\
\end{tabular} & 4 & 3 & 5 & 3 & 3 \\
\hline Empathy & $\begin{array}{l}4 \\
\text { participants }\end{array}$ & 5 & 6 & 2 & 4 & 2 \\
\hline Social skills & $\begin{array}{l}4 \\
\text { participants }\end{array}$ & 5 & 7 & 3 & 2 & 2 \\
\hline \multicolumn{7}{|l|}{ Table 1} \\
\hline
\end{tabular}

\section{Data Analysis And Discussion}

From the results stated above, it is obvious that in most of the areas of emotional intelligence : self awareness, self regulation, empathy and social skills, more than $50 \%$ of the participants reported the average score 4-6, which indicates that the participants need improvement in these areas. The area of motivation produced slightly different results in terms of numbers (12 participants reported the score 4-5). However, the number of participants who reported the average score 3 in this area was significant.

From the chart above, it can be seen that a significant number of participants in the study reported that they have higher scores which means lower 
emotional intelligence abilities in several different areas. The analysis of the self awareness dimension shows that in total, 13 participants reported the average number of 6,5 , or 4 , which indicates lower emotional intelligence abilities in the area of self- awareness. The average score of 3 was reported by 4 participants, while 6 participants out of 23 reported the results of 1 and 2 , which means high aptitude. Out of 23 participants, 19 stated that they believe that the ability to be aware of their strengths and weaknesses and develop deeper understanding of them is helpful.

In terms of self-regulation, 14 participants reported the average score 4-6, 5 participants reported the score 3 and 4 participants the scores 1 or 2 . Out of 23 participants, 20 participants confirmed that they believe that learning to understand and to manage anger or criticism or assume responsibility more effectively will support them as learners and future professionals.

According to the inventory, in the area of motivation, 12 participants reported the average result of 4-6, 5 reported the average score of 3 and 4 the average score of 4 . The area of motivation and ability to motivate self and others was considered to be important by 16 participants of the study. Moreover, even the participants who reported the average score 1-2 believed that they would benefit from motivational strategies.

The items assessing the area of empathy showed that 15 participants had the average score of 4-6, 2 participants had the average score 3 and 6 the average score of 1-2. Finally, the social skills area questionnaire items produced the following results: 16 participants reported an average score 4-6, 3 participants reported the score 3 and 4 participants reported the average score 1-2. The majority of participants (18) confirmed during the informal interview, that they consider social skills, including leadership skills and the ability to communicate and understand other individuals effectively, are very important.

\section{Conclusions}

According to the participants' answers and reported average scores, it is obvious that developing awareness and providing support for emotional intelligence development is considered to be important for future professionals and workers. One approach would be to design a program or a specific course in a formal educational setting which will aim to support emotional intelligence development. However, curriculum as well as syllabus design in a formal educational setting very often depends on various factors. Among them, the following can be mentioned: government requirements, school 
and University programs, job market and academic offers. Clearly, finding the balance among these factors and offering courses or curricula which will focus on emotional intelligence development can be perceived as difficult, unattainable or unrealistic. On the other hand, it is possible to incorporate teaching practices, tasks or activities within a framework of a program or course which will focus on emotional intelligence awareness or development.

\section{Recommendations And Ways Of Relating Emotional Intelligence And Language Learning}

The previous studies indicated that a link between learning or language learning and emotional intelligence can be established in formal educational setting. Establishing the link between emotional intelligence and successful language learning is among the aims of this study. Therefore, this article suggests several teaching strategies and activities which can foster the development of emotional intelligence areas:

\section{Developing self awareness}

Different types of activities can improve learner's self awareness and foster better understanding of self. These activities possibly include vocabulary related to feelings and emotions, role plays and dialogues, working on a reading text and character analysis related to the text. The activities which can facilitate development of self awareness also include paragraph and essay writing, personal descriptions and debates or talks where individuals express their point of view on a controversial topic.

\section{Developing self regulation}

Various activities can contribute to development of self-regulation. Among them, task based activities or problem solving activities as well as group work or pair work can facilitate learners' engagement in certain tasks and assuming roles (for instance group leader role) which bestow responsibility and commitment on individual learners. These tasks engage the learners in meaningful situations which require of them practical solutions and cooperation with other group members.

\section{Developing motivation}

A number of teaching practices and techniques can foster learners' intrinsic and extrinsic motivation. Selecting tasks and topics which appeal to learners' 
interest and preference, emphasizing and addressing learners' personal goals and objectives, personalizing the lessons and topics and enabling learners to identify with specific topics and tasks enhance motivation and emotional intelligence.

\section{Developing empathy}

A series of activities can be used to foster empathy and develop this area of emotional intelligence in language learning and formal educational setting. Topic which involves ethical issues or personal dilemmas, debates and discussions, role plays and analysis of characters in stories or texts can be used to foster empathy in language learners and promote their understanding of others.

\section{Developing social skills}

This particular area involves the development of skills necessary to interact with others and demonstrate proper behaviors in certain situations. Apart from role plays, in class discussion as and debates which were mentioned before, other activities can be used. For instance, delivering presentations and providing feedback to the presentations delivered by others enables students to demonstrate knowledge and conduct research on a certain topic. However, it also enables them to think about proper expression, content and body language. Implementing activities such as mock job interview, simulation of a brief staff meeting, or discussion trying to resolve a conflict between two individuals require from the learners to develop social skills as well as emotional intelligence.

Among the conclusions which can be drawn from this article is that emotional intelligence aspects are needed in individual development and further careers. It is also important to raise the awareness of teachers and learners of the aspects of emotional intelligence and to suggest ways to foster and enhance these skills via various teaching practices and language learning.

\section{References}

- Carmeli, A. (2003). The relationship between emotional intelligence and work attitudes, behavior and outcomes. Journal of managerial psychology, $18,788-813$.

- Emotional Intelligence Questionnaire (2013) developed by Anaptys, The Development Practice (2013). Retrieved from 
- http://www.centralpho.org.nz/Portals/0/Health\%20Services/Transformational\%20Leadership/Emotional\%20Intelligence\%20Questionnaire.pdf

- Goleman, D. (1995). Emotional intelligence: Why it can matter more than $I Q$. New York: Bantam Books.

- Mayer, J. D. \& Salovey, P. (1997). What is emotional intelligence? In P. Salovey \& D. Sluyter (Eds). Emotional Development and Emotional Intelligence: Implications for Educators, 3-31. New York: Basic Books.

- Mayer, J.D., Caruso, D., Ciarroci, J., Freedman,J., Gardner,K. J., Hetley, R., Landy,F., Michela, J., Salovey, P. ( 2012). Emotional Intelligence Information. Site Dedicated to Communicating Scientific Information about Emotional Intelligence, Including Relevant Aspects of Emotions, Cognition, and Personality. Retrieved from http://www.unh.edu/emotional intelligence/ei $\% 20$ What $\% 20$ is $\% 20 \mathrm{EI} / \mathrm{ei} \% 20$ fourbranch.htm

- Pishghadam R, 2009. A quantitative analysis of the relationship between emotional intelligence and foreign language learning. Electronic Journal of Foreign Language Teaching. 6(1), 31-41. Retrieved from http://e-flt. nus.edu.sg/v6n12009/pishghadam.pdf

- Marquez, P. G., Martin, R. P., \& Bracket, M. A. (2006). Relating emotional intelligence to social competence and academic achievement in high school students. Psichothema, 8(Supl.), 18-28. Retrieved from http:// www.psicothema.com/pdf/3286.pdf

- Salovey, P., Mayer,J.D.(1990). Emotional intelligence. Imagination, cognition, and personality, 9,185-211.

- Zarafshan, M. \& Ardeshiri, M (2012).Relationship between Emotional Intelligence, Language Learning Strategies and English Proficiency among Iranian EFL University Students, Journal of Educational and Instructional Studies in The World, 2 (3), 5-14. Retrieved from https://pdfs.semanticscholar.org/a271/a136d491108e35a1e540b302d7b43e49bf3b.pdf 